\title{
Perforated Peptic Ulcer Disease: A Review of History and Treatment
}

\author{
Mariëtta J.O.E. Bertleffa Johan F. Lange ${ }^{b}$ \\ a Department of Plastic and Reconstructive Surgery, Academic Hospital Maastricht, Maastricht, and \\ ${ }^{b}$ Department of Surgery, Erasmus University Medical Centre Rotterdam, Rotterdam, The Netherlands
}

\section{Key Words}

Perforated peptic ulcer $\cdot$ Peptic ulcer disease $\cdot$ Historical review

\begin{abstract}
Background: In the last one hundred years much has been written on peptic ulcer disease and the treatment options for one of its most common complications: perforation. The reason for reviewing the literature was evaluating most common ideas on how to treat perforated peptic ulcers (PPU) in general, opinions on conservative treatment and surgical treatment and summarizing ideas about necessary pre-, perand postoperative proceedings. Method: All relevant articles found by Medline, Ovid and PubMed search were used. Results: A hundred articles written between 1929 and 2009 were reviewed. Of these, 9 were about the history of treatment, 7 about conservative treatment, and 26 were about the surgical procedure of which 8 were addressing laparoscopic correction. Overall there is no consensus, but some advice is given. For conservative treatment there are only a few indications. Use of an omental patch is recommended, irrigation and drainage are not. Laparoscopic correction of PPU as well as for definitive ulcer surgery has many advan-
\end{abstract}

tages. Conclusions: Surgery for PPU is still a subject of debate despite more than an era of published expertise, indicating the need for establishing guidelines.

Copyright $\odot 2010$ S. Karger AG, Basel

\section{History}

For thousands of years healthy people have had acute abdominal pain, nausea, vomiting and diarrhea followed by death in a few hours or days. Often these symptoms were attributed to poisoning and people have been sent to prison for this [1]. King Charles I's daughter, HenrietteAnne, died suddenly in 1670 (at 26 years of age) after a day of abdominal pain and tenderness. Since poisoning was suspected autopsy was performed revealing peritonitis and a small hole in the anterior wall of the stomach. However, the doctors had never heard of a perforated peptic ulcer (PPU) and attributed the hole in the stomach to the knife of the dissector $[1,2]$. Necropsies were first allowed since 1500 and became more routine between 1600 and $1800[2,3]$. As a consequence, perforation of the stomach was more often observed. Johan Mikulicz-Radecki (1850-1905), often referred to as the first surgeon

\section{KARGER}

Fax +4161306 1234 E-Mail karger@karger.ch www.karger.com
(ㄷ) 2010 S. Karger AG, Basel

0253-4886/10/0273-0161\$26.00/0

Accessible online at:

www.karger.com/dsu
Mariëtta J.O.E. Bertleff

Department of Plastic and Reconstructive Surgery

P. Debeyelaan 25

NL-6229 HX Maastricht (The Netherlands)

Tel. +31 43517 7481, Fax +31 43387 5612, E-Mail doc.bert@ online.nl 
Table 1. Demographics of patients with perforated peptic ulcer disease $[12,13,16,31,41-43,45,49,51,52,58-100]$

\begin{tabular}{llr}
\hline & Total $(\mathrm{n}=2,784)$ & $\mathrm{n}$ \\
\hline Age, years & 48 & 2,328 \\
Male, \% & 79 & 2,678 \\
History of ulcer, \% & 29 & 1,140 \\
History of NSAID use, \% & 20 & 1,109 \\
Smokers, \% & 62 & 472 \\
Alcohol use, \% & 29 & 198 \\
ASA I, \% & 35 & 1,120 \\
ASA II, \% & 37 & 1,060 \\
ASA III, \% & 20 & 1,060 \\
ASA IV, \% & 9 & 1,030 \\
Boey 0, \% & 59 & 513 \\
Boey 1, \% & 23 & 513 \\
Boey 2, \% & 16 & 513 \\
Boey 3, \% & 2 & 513 \\
Shock at admission, \% & 7 & 1,107 \\
Symptoms $>$ 24 h, \% & 11 & 723 \\
Duration of symptoms, h & 13.6 & 837 \\
Free air on X-ray, \% & 85 & 510 \\
WBC & 12.3 & 147 \\
\hline
\end{tabular}

who closed a PPU by simple closure, said: 'Every doctor, faced with a perforated duodenal ulcer of the stomach or intestine, must consider opening the abdomen, sewing up the hole, and averting a possible inflammation by careful cleansing of the abdominal cavity' [4]. Surprisingly enough, treatment has not changed much since, still consisting of primary closure of the perforation by a single stitch suture and a convenient tag of adjacent omentum on top of this [5-8]. Although this therapy sounds very simple PPU still remains a dangerous surgical condition, associated with high morbidity and mortality, not to be underestimated [9].

\section{Clinical Presentation and Investigation}

In 1843, Edward Crisp was the first to report 50 cases of PPU and accurately summarized the clinical aspects of perforation, concluding: 'The symptoms are so typical, I hardly believe it possible that anyone can fail to make the correct diagnosis' [10]. Patients with PPU have a typical history of sudden onset of acute, sharp pain usually located in the epigastric area and sometimes with shoulder pain, indicating free air under the diaphragm [11]. Bases on collected data from 52 papers on PPU clinical characteristics have been summarized in table 1 . The typical patient with PPU is male with an average age of 48 years. He may have a history of peptic ulcer disease (PUD) (29\%), or nonsteroidal anti-inflammatory drugs (NSAIDs) usage (20\%). Vomiting and nausea are present in $50 \%$ of the cases. At physical examination, pulse might be quickened, but seldom goes beyond $90 \mathrm{bpm}$. About $5-10 \%$ of patients experience shock with a mean arterial pressure of less than $80 \mathrm{~mm} \mathrm{Hg}$ [12]. Hypotension is a late finding as is high fever. Obliteration or complete absence of liver dullness was only noted in $37 \%$, so as a diagnostic tool, this has its limitations [7]. In blood analysis a moderate leukocy tosis will be found. The main reason for taking a blood sample is excluding other diagnoses like pancreatitis [4]. An X-ray of the abdomen/thorax in the standing position will reveal free air under the diaphragm in about $80-85 \%[7,13]$. Some centers perform abdominal ultrasonography, or computerized tomography (CT) scans with oral contrast [14]. With current radiological techniques, $80-90 \%$ of cases are correctly diagnosed [12]. As soon as diagnosis is made resuscitation is started with large volume crystalloids, nasogastric suction to empty the stomach, and administration of broad-spectrum antibiotics $[13,15]$. When PPU has been diagnosed, there are a few different therapeutic options to be taken into consideration [12]. Firstly, it must be evaluated if the patient is suitable for surgery or if conservative treatment should be considered instead. If surgery is indicated, is a simple closure with or without omentoplasty sufficient or is there a need for definitive ulcer surgery and if so which specific operation is indicated? Finally, can the operation be performed laparoscopically or are there risk factors that would make laparotomy a safer option $[12,16]$ ?

\section{Pathogenesis}

The pathogenesis of PUD may best be considered as representing a complex scenario involving an imbalance between defensive (mucus-bicarbonate layer, prostaglandins, cellular renovation, and blood flow) and aggressive factors (hydrochloric acid, pepsin, ethanol, bile salts, some medications, etc.) [15]. In recent years, Helicobacter pylori infection and NSAIDs have been identified as the two main causes of peptic ulcer [17]. The use of crack cocaine has also led to an increase in PPU, but with a different underlying mechanism, since PPU secondary to the use of crack cocaine is caused by ischemia of the gastric mucosa, and treatment of these perforations does not require acid reducing definitive surgery [12]. Three clinical phases in the process of PPU can be distinguished [4]: 
Phase 1: Chemical peritonitis/contamination. The perforation causes a chemical peritonitis. Acid sterilizes the gastroduodenal content; it is only when gastric acid is reduced by treatment or disease (gastric cancer) that bacteria and fungi are present in the stomach and duodenum.

Phase 2: Intermediate stage. After 6-12 h many patients obtain some relief of pain. This is probably due to the dilution of the irritating gastroduodenal contents by ensuing peritoneal exudates.

Phase 3: Intra-abdominal infection. After $12-24 \mathrm{~h}$ intra-abdominal infection supervenes.

\section{Epidemiology}

Perforation occurs in $2-10 \%$ of patients with PUD and accounts for more than $70 \%$ of deaths associated with PUD. Perforation is often the first clinical presentation of PUD [18]. The incidence of duodenal perforation is $7-10$ cases $/ 100,000$ adults per year $[9,15,16,19-22]$. The perforation site usually involves the anterior wall of the duodenum (60\%), although it might occur in antral (20\%) and lesser-curvature gastric ulcers (20\%) [19]. Duodenal ulcer is the predominant lesion of the western population, whereas gastric ulcers are more frequent in oriental countries, particularly in Japan. Gastric ulcers have a higher associated mortality and a greater morbidity resulting from hemorrhage, perforation and obstruction [17]. PPU used to be a disorder mainly of younger patients (predominantly males), but recently the age of PPU patients is increasing (predominantly females) $[16,20]$. The current peak age is $40-60$ years [16]. The need for surgery for PPU has remained stable or even increased and the mortality of peptic ulcer surgery has not decreased since the introduction of $\mathrm{H}_{2}$ receptor antagonists and peptic ulcers are still responsible for about 20,000-30,000 deaths per year in Europe $[19,23]$. This may be due to an increase in use of aspirin and/or NSAIDs [12].

\section{Role of Helicobacter pylori}

Until the discovery of the role of $H$. pylori in gastric and peptic ulcers by Barry J. Marshall and Robin Warren in 1982, stress and life style factors were believed to be the most important factors contributing to PUD and PPU [24]. H. pylori infection can be held responsible in more than $90 \%$ of duodenal ulcers and in up to $80 \%$ of gastric ulcers $[17,24]$. H. pylori infection and the accompanying inflammation disrupts the inhibitory control of gastrin release by decreasing antral somatostatin, and this is more marked if the infecting organism is a cagA-positive strain [19]. The resulting increase in gastrin release and gastric acid secretion is a key mechanism by which the H. pylori infection induces PUD [19]. In most instances, infection with $H$. pylori seems to be acquired in early childhood. In contrast to many other infections, the immune system does not contribute to the healing $[3,17]$. Another problem with eradicating $H$. pylori is that it is not only located on the surface of the gastric mucosa but also in the layer of mucus protecting it. In 1994, the National Institutes of Health Consensus Development Panel on Helicobacter pylori in Peptic Ulcer Disease recommended that ulcer patients positive for $H$. pylori should be treated with antimicrobial agents [25]. The type, number of drugs given and treatment duration differ enormously [25]. Although the problem of antibiotic resistance of $H$. pylori is increasing, combination therapies such as metronidazole with clindamycin or metronidazole with tetracycline can achieve eradication rates of $80 \%$ or more $[19,26]$. According to the Maastricht III consensus report, first line treatment for $H$. pylori infection should be triple therapy which should compromise a proton pump inhibitor (PPI) plus clarithromycin plus amoxicillin or metronidazole $[17,27]$. Monotherapy by just giving antibiotics has proven not to be successful ( $<30 \%$ eradication rate) [17]. Traditionally, peptic ulcer is diagnosed endoscopically, but this is an expensive tool and not well tolerated by patients [22]. The carbon-13urea breath test is expensive, but represents a reliable indicator of $H$. pylori infection. The preferred method to diagnose $H$. pylori is by taking peroperative biopsies [22]. Even in patients with PPU and NSAID usage, it is advisable to look for the presence of $H$. pylori, since it can be eradicated easily. To avoid missing gastric cancer, gastroendoscopy should be performed in patients $>45$ years of age with alarming features like weight loss, anemia, or dysphagia [17].

\section{Current Management Perforated Peptic Ulcer}

\section{Nonoperative Management}

Conservative treatment is known as the Taylor method and consists of nasogastric aspiration, antibiotics, intravenous fluids and nowadays $H$. pylori triple therapy $[23,26]$. In 1946, Taylor presented the first series of successful outcome of conservatively treated patients with PPU, based on the theory that effective gastric decom- 


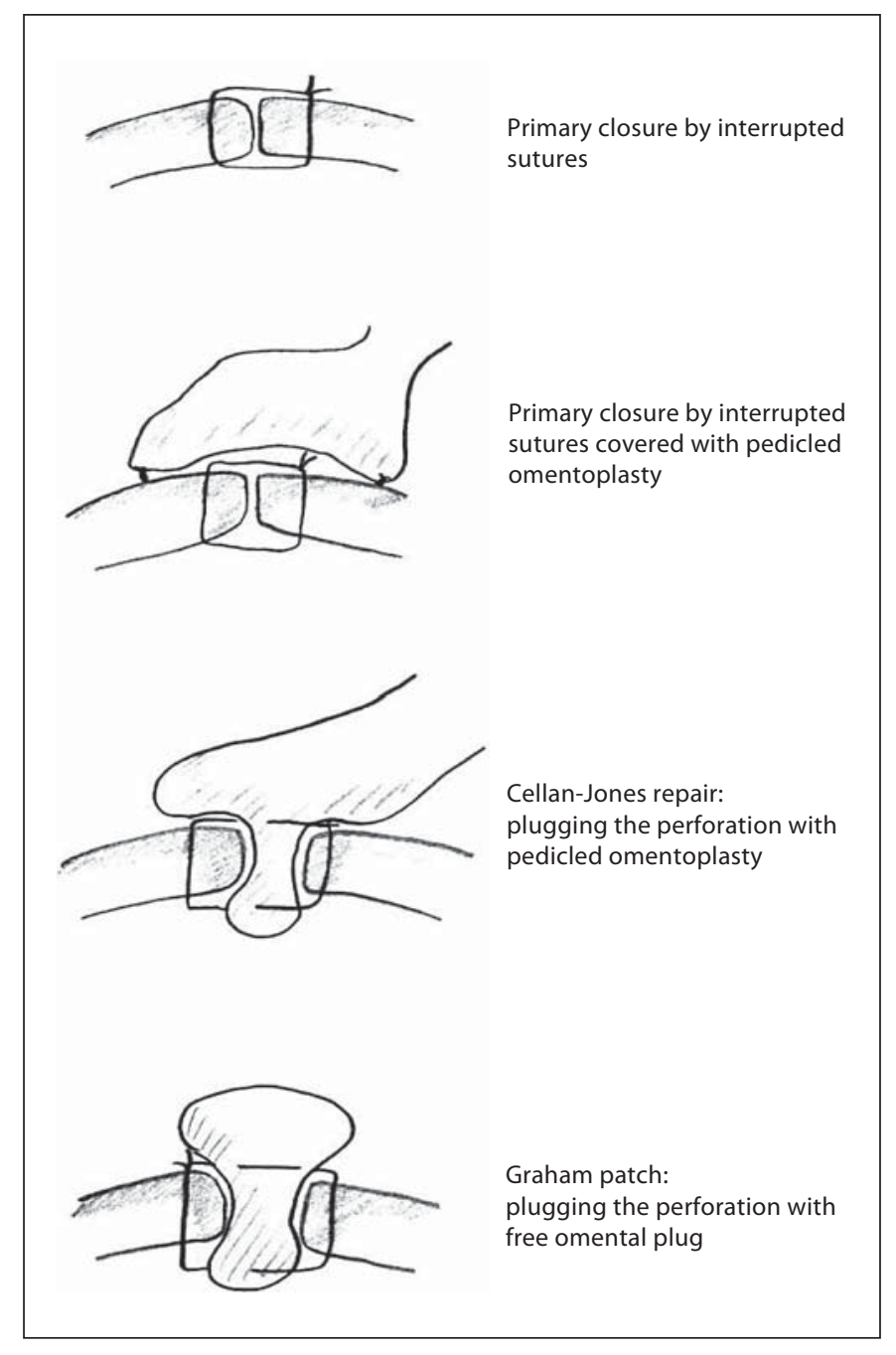

Fig. 1. Different suture techniques for closure of the perforation.

pression and continuous drainage will enhance self-healing $[9,26]$. The fundamental idea for conservative treatment came from Crisp who in 1843 noted that perforations of the stomach were filled up by adhesions to the surrounding viscera which prevented leakage from the stomach into the peritoneum [26]. Since then, many reports have been published on this topic, with different success rates [9]. But still there is an ongoing debate whether PPU generally needs to be operated on or not. It has been estimated that about $40-80 \%$ of the perforations will seal spontaneously and overall morbidity and mortality are comparable $[19,23,26,28]$. However, delaying the time point of operation beyond $12 \mathrm{~h}$ after the onset of clinical symptoms will worsen the outcome in PPU [9, 19]. Also in patients $>70$ years of age conservative treat- ment is unsuccessful with a failure rate as high as $67 \%[9$, 28]. Shock at admission and conservative treatment were associated with a high mortality rate $(64 \%)[9,23]$. Patients likely to respond well to conservative treatment can be selected by performing a gastroduodenogram as described by Donovan et al. [26]. Nonsurgical treatment in these patients, who had proven sealing of their perforation site, was safe, only resulting in 3\% intra-abdominal abscess formation and $<2 \%$ repeat leak [26]. The advantages of conservative treatment are avoidance of operation with associated morbidity caused by surgery and anesthesia, reduction in formation of intra-abdominal adhesion induced by surgery which makes elective surgery for PUD or for other indications in a later phase less complicated and hospital stay perhaps shorter [29]. However, there are also studies that showed a prolonged hospital stay after conservative treatment $[13,19]$. Disadvantages are a higher mortality rate in case conservative treatment fails. Another disadvantage is the lack of the benefit of laparoscopy or laparotomy as a diagnostic tool in case the patient was misdiagnosed [28, 29]. Finally, one always has to bear in mind that PPU can be a symptom of gastric cancer, so if conservative treatment has been chosen after a few weeks endoscopy should be performed $[9,28]$. In conclusion, one can say that nonoperative treatment is limited to patients $<70$ years of age who are not eligible for surgical repair due to associated morbidity, with documented contrast studies showing that the perforation has sealed completely. When the patient is in shock or when the time point between perforation and 'start of treatment' is $>12 \mathrm{~h}$, simple closure should be the first treatment of choice.

\section{Simple Suture}

Open Repair Technique. All surgical procedures start by giving prophylactic antibiotics at induction of anesthesia. In conventional surgery, an upper midline incision is performed. Identification of the site of perforation is not always easy: sometimes a perforation has occurred at the dorsal site of the stomach, only to be detected after opening of the lesser sac through the gastrocolic ligament. Also, double perforations can occur. In case of a gastric ulcer, a biopsy is taken to exclude gastric cancer. Simple closure of the perforation can be done in different ways (fig. 1): simple closure of the perforation by interrupted sutures without omentoplasty or (free) omental patch, simple closure of the perforation with a pedicled omentum sutured on top of the repair, representing omentoplasty, a pedicled omental plug drawn into the perforation after which the sutures are tied over it, and 
finally the free omental patch after Graham. The repair can be tested by either filling the abdomen with warm saline and inflating some air into the nasogastric tube. If no bubbles appear, the perforation has been sealed appropriately. Also, dye can be injected through the nasogastric tube [30]. Thorough peritoneal toilet is then performed. A drain is not left routinely [31]. The abdominal wound can be infiltrated with bupivacaine $0.25 \%$ at the end of the procedure.

Omentoplasty or Omental Patch: Necessary or Not? Cellan-Jones [32] published an article in 1929 entitled 'a rapid method of treatment in perforated duodenal ulcers'. Treatment of choice at that time was, after excision of friable edges if indicated, the application of purse string sutures and on top an omental graft. An encountered problem was narrowing of the duodenum. To avoid this, he suggested omentoplasty without primary closure of the defect. His technique consisted of placing 4-6 sutures, selecting a long omental strand passing a fine suture through it, the tip of the strand is then anchored in the region of the perforation and finally the sutures are tied off [32]. It was not until 1937 that Graham published his results with a free omental graft [33]. He placed three sutures with a piece of free omentum laid over these sutures, which are then tied. No attempt is made to actually close the perforation [33]. The omental graft provides the stimulus for fibrin formation. His approach has been the golden standard since [34]. Very often surgeons mention they used a Graham patch, but they actually mean they used the pedicled omental patch described by Cellan-Jones [32]. Schein [4] could not have outlined it any clearer: 'Do not stitch the perforation but plug it with viable omentum and patch a perforated ulcer if you can, if you cannot, then you must resect'.

Irrigation of the Peritoneal Cavity. Although some surgeons doubt the usefulness of irrigation, nothing has been found in the literature supporting this theory. Generally, it is reflected on to be one of the most important parts of the surgery and irrigation with 6-10 liters and even up to 30 liters of warm saline are recommended [16]. However, the rational for the routine use of intraoperative peritoneal lavage seems to be more a historically based custom lacking any evidence-based support [35].

Drainage or Not. There seems to be no unanimity of opinion on this topic $[16,30]$. In a questionnaire $80 \%$ of the responders answered that they would not leave a drain [30]. A drain will not reduce the incidence of intra-abdominal fluid collections or abscesses [30]. On the other hand, the drain site can become infected (10\%) and can cause intestinal obstruction $[30,36]$. Often, a drain is left as a sentinel. However, in case of suspected leakage, a CT scan will provide all the information needed, probably better than a nonproductive drain.

\section{Definitive Surgery}

Indications for elective surgery are still not defined [19]. The number of elective procedures performed for PUD has declined by more than $70 \%$ since the 1980s [19, 22]. The results of a questionnaire with 607 responders showed that only $0.3 \%$ of the surgeons routinely perform a vagotomy for duodenal ulcer complications and 54.5\% mentioned they never include it [37]. Reasons for decline in definitive ulcer surgery are: lower recurrence rate of PUD and PPU because of good results of $H$. pylori eradication and elimination of NSAID use. Also patients nowadays operated for PPU are older with higher surgical risk which make them less suitable candidates for definitive ulcer surgery. Finally, many surgeons practicing today have limited experience with definitive ulcer operations [22]. Patients in whom definitive ulcer surgery should be considered are those with PPU who are found to be $H$. pylori-negative, or those with recurrent ulcers despite triple therapy $[12,19,26,38,39]$. In these patients, a parietal cell vagotomy is recommended if necessary combined with anterior linear gastrectomy [40]. This procedure can be safely and relatively easily performed laparoscopically $[19,22]$.

\section{Laparoscopy}

Since the 1990s laparoscopic closure of a PPU has been described. Laparoscopic surgery offers several advantages. First of all, a laparoscopic procedure serves as a minimally invasive diagnostic tool [41]. Other benefits from laparoscopic repair are postoperative pain reduction and less consumption of analgesics and a reduction in hospital stay [42]. Also, a reduction in wound infections, burst abdomen and incisional hernia due to shorter scars has been noted $[16,42]$. Avoiding upper laparotomy might lower the incidence of postoperative ileus and chest infections $[16,42]$. Drawbacks are a prolonged operating time, higher incidence of re-operations due to leakage at the repair site and a higher incidence of intra-abdominal collection secondary to inadequate lavage $[16,42,43]$. If the presence of these fluid collections has any clinical relevance is unclear. The higher incidence of leakage might be caused by the difficulty of the laparoscopic suturing procedure. First of all, this emphasizes the need for a dedicated laparoscopically trained surgeon to perform this procedure [13]. Alternative techniques to simplify the suturing process have been thought of $[13,42]$. Some lapa- 
Table 2. Overview of complications after surgery for PPU $[13,16$, $19,20,42,43,51-55]$

\begin{tabular}{lc}
\hline Complication & \% incidence \\
\hline Pneumonia & $3.6-30$ \\
Wound infection & $10-17$ \\
Urinary tract infection & $1.4-15$ \\
Suture leak & $2-16$ \\
Abscess formation & $0-9$ \\
Heart problems & \\
$\quad$ (myocardial infarction, heart failure) & 5 \\
Ileus & $2-4$ \\
Fistula & $0.5-4$ \\
Wound dehiscence & $2.5-6$ \\
Biliary leak & 4.9 \\
Bleeding & 0.6 \\
Re-operation & $2-9$ \\
Sepsis & 2.5 \\
Stroke & 4 \\
Death & $5-11$ \\
\hline
\end{tabular}

Table 3. Boey's score related to morbidity and mortality

\begin{tabular}{llc}
\hline & Morbidity rate, \% & Mortality rate, \% \\
\hline Boey 0 & 17.4 & 1.5 \\
Boey 1 & 30.1 & 14.4 \\
Boey 2 & 42.1 & 32.1 \\
Boey 3 & & 100 \\
\hline
\end{tabular}

roscopic surgeons use omentopexy alone [12, 41]. Sutureless techniques have been tried, in which fibrin glue alone or a gelatin sponge has been glued into the ulcer [12]. The downside of this technique is that it can only be used to close small perforations. To overcome this problem, a biodegradable patch that can be cut into any desirable size has been tested in rats with good results [44]. Finally, combined laparoscopic-endoscopic repair has been described as well [45].

\section{Postoperative Management}

In reviewing the literature, all patients receive nasogastric probes for at least $48 \mathrm{~h}$ [16]. This, however, seems to be a more 'common practice' than evidence-based medicine [46]. A recently published Cochrane review concludes that routine nasogastric decompression does not accomplish any of its intended goals and should only be applied in selected cases, which has been supported by other trials as well [46-48]. This also means that oral feeding can be started early, as in colorectal surgery, and that waiting for 3 days, as is often done according to protocol, is unnecessary $[48,49]$. As can be seen in table 2 , wound infections represent the second most common complication after surgery for PPU. Also, the incidence of sepsis is $2.5 \%$. Preoperative intravenous administration of antibiotics has proven to lower the overall infection rate [50]. Though for most surgical procedures a single dose seems to be sufficient, in the case of $H$. pylori infection triple therapy is recommended consisting of a PPI combined with clarithromycin and amoxicillin for 14 days $[16,27,49,50]$. Upper gastrointestinal endoscopy is suggested to be performed after 6 weeks to assess healing of the ulcers and to evaluate H. pylori status [49].

\section{Postoperative Complications}

The most commonly observed postoperative complication was pneumonia followed by wound infection. An overview of all the complications and their incidences based on literature reviews is listed in table $2[13,16,19$, $20,42,43,51-55]$.

\section{Risk Factors Influencing Outcome}

Mortality after surgery for PPU is between 6 and 10\% [20]. There are four main factors which can increase this mortality rate even up to $100 \%$. These are age $>60$ years, delayed treatment $(>24 \mathrm{~h}$ ), shock at admission (systolic $\mathrm{BP}<100 \mathrm{~mm} \mathrm{Hg}$ ) and concomitant diseases [19, 21]. Also, gastric ulcers are associated with a two- to threefold increased mortality risk $[19,22]$. Boey's score, which is a score based on scoring factors as shock on admission, confounding medical illness, and prolonged perforation, has been found to be a useful tool in predicting outcome (table 3) [16, 23, 39, 51].

\section{Perforated Peptic Ulcer in the Elderly}

Mortality rate after surgery for PPU is three to five times higher in the elderly (up to 50\%) [56]. This can be explained by the occurrence of concomitant medical diseases but also by difficulties in making the right diagnosis resulting in a delay of $>24 \mathrm{~h}$ [56]. In case of a perforated gastric ulcer or recurrent PUD (hemi)gastrectomy 
with vagotomy might be indicated, but overall simple closure is a safe procedure and there seems to be no need for definitive surgery in this group of patients since ulcer recurrence is only $14 \%[12,56,57]$.

\section{Conclusion}

Surgery for PPU still is a subject of debate despite more than an era of published expertise. Reviewing different policies regarding for instance the indication for conservative treatment, sense or no sense of drains, the need for omentoplasty or not, performing the procedure laparoscopically and the need for definitive ulcer surgery, might contribute to establishing consensus. Reviewing results of laparoscopic correction of PPU and correction by upper laparotomy one may conclude that the complications seen after laparoscopic procedure (longer operation time and higher incidence of re-leakage), which can be reduced by allowing only surgeons trained in laparoscopy to perform this surgery, do not outweigh the benefits of performing this procedure laparoscopically (lower pain, morbidity and mortality), even in the elderly. Therefore, a laparoscopic procedure should be the first choice.

\section{References}

1 Baron JH: Paintress, princess and physician's paramour: poison or perforation? J R Soc Med 1998;91:213-216.

$\checkmark 2$ Baron JH: Peptic ulcer. Mount Sinai J Med 2000;67:58-62.

-3 Baron JH, Sonnenberg A: Publications on peptic ulcer in Britain, France, Germany and the US. Eur J Gastroenterol Hepatol 2002;14: 711-715.

4 Schein M: Perforated peptic ulcer; in (ed.): Schein's Common Sense Emergency Abdominal Surgery. Part III. Berlin, Springer, 2005, pp 143-150.

5 Rayner HH: Treatment of perforated peptic ulcer. Lancet 1930;ii:107-108.

-6 Sangster AH: Perforated peptic ulcer: an analysis of 100 consecutive cases. Lancet 1939;23:1311-1313.

7 Berson HL: Acute perforated peptic ulcers: an eighteen-year survey. Am J Surg 1942;16: 385-394.

$\checkmark 8$ Hastings N, Machida R: Perforated peptic ulcer: results after simple surgical closure. Am J Surg 1961;102:136-142.

9 Conservative management of perforated peptic ulcer. Lancet 1989;16:1429-1430.

$>10$ Lau WY, Leow CK: History of perforated duodenal and gastric ulcers. World J Surg 1997; 21:890-896.

11 Birks PM: Perforated peptic ulcer treated without operation. Lancet 1947;iv:467-468.

-12 Lagoo S, McMahon RL, Kakihara M, Pappas TN, Eubanks S: The sixth decision regarding perforated duodenal ulcer. JSLS 2002;6:359368

-13 Lau WY: Perforated peptic ulcer: open versus laparoscopic repair. Asian J Surg 2002;25: 267-269.

- 14 Fujii Y, Asato M, Taniguchi N, Shigeta K, Omoto K, Itoh K, Suzukawa M: Sonographic diagnosis and successful nonoperative management of sealed perforated duodenal ulcer. J Clin Ultrasound 2003;31:55-58.
15 Ramakrishnan K, Salinas RC: Peptic ulcer disease. Am Fam Physician 2007;76:10051012 .

16 Lunevicius R, Morkevicius M: Management strategies, early results, benefits, and risk factors of laparoscopic repair of perforated peptic ulcer. World J Surg 2005;29:1299_ 1310.

17 Sivri B: Trends in peptic ulcer pharmacotherapy. Fundam Clin Pharmacol 2004;18: 23-31.

-18 Druart ML, Van Hee R, Etienne J, et al: Laparoscopic repair of perforated duodenal ulcer: a prospective multicenter clinical trial. Surg Endosc 1997;11:1017-1020.

19 Zittel TT, Jehle EC, Becker HD: Surgical management of peptic ulcer disease today: indication, technique and outcome. Langenbecks Arch Surg 2000;385:84-96.

$>20$ Imhof M, Epstein S, Ohmann C, Roher HD: Duration of survival after peptic ulcer perforation. World J Surg 2008;32:408-412.

21 Sarosi GA Jr, Jaiswal KR, Nwariaku FE, Asolati M, Fleming JB, Anthony T: Surgical therapy of peptic ulcers in the 21st century: more common than you think. Am J Surg 2005; 190:775-779.

22 Harbison SP, Dempsey DT: Peptic ulcer disease. Curr Probl Surg 2005;42:346-454.

-23 Bucher P, Oulhaci W, Morel P, Ris F, Huber $\mathrm{O}$ : Results of conservative treatment for perforated gastroduodenal ulcers in patients not eligible for surgical repair. Swiss Med Wkly 2007;137:337-340.

24 Ahmed N: 23 years of the discovery of Helicobacter pylori: is the debate over? Ann Clin Microbiol Antimicrob 2005;4:17.

-25 Fischbach LA, Goodman KJ, Feldman M, Aragaki C: Sources of variation of Helicobacter pylori treatment success in adults worldwide: a meta-analysis. Int J Epidemiol 2002;31:128-139.
26 Donovan AJ, Berne TV, Donovan JA: Perforated duodenal ulcer: an alternative therapeutic plan. Arch Surg 1998;133:1166-1171.

27 Malfertheiner P, Megraud F, O'Morain C, Bazzoli F, El-Omar E, Graham D, Hunt R, Rokkas T, Vakil N, Kuipers EJ: Current concepts in the management of Helicobacter pylori infection: the Maastricht III Consensus Report. Gut 2007;56:772-781.

$>28$ Crofts TJ, Park KG, Steele RJ, Chung SS, Li AK: A randomized trial of nonoperative treatment for perforated peptic ulcer. N Engl J Med 1989;320:970-973

-29 Truscott B, Withycombe JFR: Perforated peptic ulcer. An assessment of the value of nonoperative treatment. Lancet 1950;13: 894-896

30 Schein M: To drain or not to drain? The role of drainage in the contaminated and infected abdomen: an international and personal perspective. World J Surg 2008;32:312-321.

>31 Siu WT, Leong HT, Law BK, Chau CH, Li AC, Fung KH, Tai YP, Li MK: Laparoscopic repair for perforated peptic ulcer: a randomized controlled trial. Ann Surg 2002;235: 313-319.

$\$ 32$ Cellan-Jones CJ: A rapid method of treatment in perforated duodenal ulcer. BMJ 1929;1076-1077.

33 Graham RR: The treatment of perforated duodenal ulcers. Surg Gynecol Obstet 1937: 235-238.

>34 Fallat ME, White MJ, Richardson JD, Flint LM: Reassessment of Graham-Steele closure in acute perforated peptic ulcer. South Med J 1983;76:1222-1224.

>35 Whiteside OJ, Tytherleigh MG, Thrush S, Farouk R, Galland RB: Intra-operative peritoneal lavage-who does it and why? Ann R Coll Surg Engl 2005;87:255-258.

>36 Pai D, Sharma A, Kanungo R, Jagdish S, Gupta A: Role of abdominal drains in perforated duodenal ulcer patients: a prospective controlled study. Aust NZ J Surg 1999;69: 210-213. 
-37 Branicki FJ: Abdominal emergencies: diagnostic and therapeutic laparoscopy. Surg Infect (Larchmt) 2002;3:269-282.

-38 Schwesinger WH, Page CP, Sirinek KR, Gaskill HV III, Melnick G, Strodel WE: Operations for peptic ulcer disease: paradigm lost. J Gastrointest Surg 2001;5:438-443.

-39 Sarath Chandra SS, Kumar SS: Definitive or conservative surgery for perforated gastric ulcer? An unresolved problem. Int J Surg 2009;7:136-139.

40 Jordan PH Jr, Thornby J: Perforated pyloroduodenal ulcers: long-term results with omental patch closure and parietal cell vagotomy. Ann Surg 1995;221:479-486; discussion 486-488.

41 Ates M, Coban S, Sevil S, Terzi A: The efficacy of laparoscopic surgery in patients with peritonitis. Surg Laparosc Endosc Percutaneous Techn 2008; 18:453-456.

$\checkmark 2$ Lau H: Laparoscopic repair of perforated peptic ulcer: a meta-analysis. Surg Endosc 2004;18:1013-1021.

43 Lunevicius R, Morkevicius M: Risk factors influencing the early outcome results after laparoscopic repair of perforated duodenal ulcer and their predictive value. Langenbecks Arch Surg 2005;390:413-420.

44 Bertleff MJ, Liem RS, Bartels HL, Robinson $\mathrm{PH}$, Van der Werff JF, Bonjer HJ, Lange JF: The 'stamp method': a new treatment for perforated peptic ulcer? Surg Endosc 2006; 20:791-793.

-45 Alvarado-Aparicio HA, Moreno-Portillo M: Multimedia article: management of duodenal ulcer perforation with combined laparoscopic and endoscopic methods. Surg Endosc 2004; 18:1394.

46 Nelson R, Edwards S, Tse B: Prophylactic nasogastric decompression after abdominal surgery. Cochrane Database Syst Rev (Online) 2007;CD004929.

-47 Daryaei P, Vaghef Davari F, Mir M, Harirchi I, Salmasian H: Omission of nasogastric tube application in postoperative care of esophagectomy. World J Surg 2009;33:773-777.

-48 St Peter SD, Valusek PA, Little DC, Snyder CL, Holcomb GW 3rd, Ostlie DJ: Does routine nasogastric tube placement after an operation for perforated appendicitis make a difference? J Surg Res 2007;143:66-69.

-49 Siu WT, Chau CH, Law BK, Tang CN, Ha PY, Li MK: Routine use of laparoscopic repair for perforated peptic ulcer. Br J Surg 2004;91: 481-484.

50 Waddell TK, Rotstein OD: Antimicrobial prophylaxis in surgery: Committee on Antimicrobial Agents, Canadian Infectious Disease Society. CMA J 1994;151:925-931.

-51 Lunevicius R, Morkevicius M: Comparison of laparoscopic versus open repair for perforated duodenal ulcers. Surg Endosc 2005;19: 1565-1571.

-52 Lam PW, Lam MC, Hui EK, Sun YW, Mok FP: Laparoscopic repair of perforated duodenal ulcers: the 'three-stitch' Graham patch technique. Surg Endosc 2005;19:1627-1630.
53 Gupta S, Kaushik R, Sharma R, Attri A: The management of large perforations of duodenal ulcers. BMC Surg 2005;5:15.

54 Rahuman MM, Saha AK, Rahim A: Experience of peptic ulcer perforation over a decade in a teaching hospital of southern Bangladesh. Ceylon Med J 2003;48:53-55.

-55 Sharma SS, Mamtani MR, Sharma MS, Kulkarni H: A prospective cohort study of postoperative complications in the management of perforated peptic ulcer. BMC Surg 2006;6:8.

56 Feliciano DV, Bitondo CG, Burch JM, Mattox KL, Jordan GL Jr, DeBakey ME: Emergency management of perforated peptic ulcers in the elderly patient. Am J Surg 1984; 148:764-767.

57 Blomgren LG: Perforated peptic ulcer: longterm results after simple closure in the elderly. World J Surg 1997;21:412-414; discussion 414-415.

58 Agresta F, Mazzarolo G, Ciardo LF, Bedin N: The laparoscopic approach in abdominal emergencies: has the attitude changed? A single-center review of a 15-year experience. Surg Endosc 2008;22:1255-1262.

59 Sanabria AE, Morales CH, Villegas MI: Laparoscopic repair for perforated peptic ulcer disease. Cochrane Database System Rev (Online) 2005;CD004778.

60 Vaidya BB, Garg CP, Shah JB: laparoscopic repair of perforated peptic ulcer with delayed presentation. J Laparoendosc Adv Surg Tech [A] 2009;19:153-156.

61 Song KY, Kim TH, Kim SN, Park CH: Laparoscopic repair of perforated duodenal ulcers: the simple 'one-stitch' suture with omental patch technique. Surg Endosc 2008; 22:1632-1635.

62 Ates M, Sevil S, Bakircioglu E, Colak C: Laparoscopic repair of peptic ulcer perforation without omental patch versus conventional open repair. J Laparoendosc Adv Surg Tech [A] 2007;17:615-619.

63 Bhogal RH, Athwal R, Durkin D, Deakin M, Cheruvu CN: Comparison between open and laparoscopic repair of perforated peptic ulcer disease. World J Surg 2008;32:23712374.

64 Kirshtein B, Bayme M, Mayer T, Lantsberg L, Avinoach E, Mizrahi S: Laparoscopic treatment of gastroduodenal perforations: comparison with conventional surgery. Surg Endosc 2005; 19:1487-1490.

65 Lunevicius R, Morkevicius M: Systematic review comparing laparoscopic and open repair for perforated peptic ulcer. Br J Surg 2005;92:1195-1207.

66 Palanivelu C, Jani K, Senthilnathan P: Laparoscopic management of duodenal ulcer perforation: is it advantageous? Indian J Gastroenterol 2007;26:64-66.

-67 Sauerland S, Agresta F, Bergamaschi R, et al: Laparoscopy for abdominal emergencies: evidence-based guidelines of the European Association for Endoscopic Surgery. Surg Endosc 2006;20:14-29.
68 Wong BP, Chao NS, Leung MW, Chung KW, Kwok WK, Liu KK: Complications of peptic ulcer disease in children and adolescents: minimally invasive treatments offer feasible surgical options. J Pediatr Surg 2006;41: 2073-2075.

69 Aali AYA, Bestoun HA: Laparoscopic repair of perforated duodenal ulcer. Middle East J Emerg Med 2002;2:1-4.

70 Agresta F, Michelet I, Coluci G, Bedin N: Emergency laparoscopy: a community hospital experience. Surg Endosc 2000;14:484487.

71 Arnaud JP, Tuech JJ, Bergamaschi R, Pessaux P, Regenet N: Laparoscopic suture closure of perforated duodenal peptic ulcer. Surg Laparosc Endosc Percut Techn 2002;12:145-147.

72 Bergamaschi R, Marvik R, Johnsen G, Thoresen JE, Ystgaard B, Myrvold HE: Open versus laparoscopic repair of perforated peptic ulcer. Surg Endosc 1999;13:679-682.

73 Bohm B, Ablassmaier B, Muller JM: Laparoscopic surgery of the upper gastrointestinal tract. Chirurg 2001;72:349-361.

74 Dubois F: New surgical strategy for gastroduodenal ulcer: laparoscopic approach. World J Surg 2000;24:270-276.

75 Freston JW: Management of peptic ulcers: emerging issues. World J Surg 2000;24:250255.

76 Gentileschi P, Rossi P, Manzelli A, Lirosi F, Susanna F, Stolfi VM, Spina C, Gaspari AL: Laparoscopic suture repair of a perforated gastric ulcer in a severely cirrhotic patient with portal hypertension: first case report. JSLS 2003;7:377-382.

77 Katkhouda N, Mavor E, Mason RJ, Campos GM, Soroushyari A, Berne TV: Laparoscopic repair of perforated duodenal ulcers: outcome and efficacy in 30 consecutive patients. Arch Surg 1999;134:845-848; discussion 849-850.

78 Khoursheed M, Fuad M, Safar H, Dashti H, Behbehani A: Laparoscopic closure of perforated duodenal ulcer. Surg Endosc 2000;14: 56-58.

79 Lau JY, Lo SY, Ng EK, Lee DW, Lam YH, Chung SC: A randomized comparison of acute phase response and endotoxemia in patients with perforated peptic ulcers receiving laparoscopic or open patch repair. Am J Surg 1998;175:325-327.

80 Lee FY, Leung KL, Lai BS, Ng SS, Dexter S, Lau WY: Predicting mortality and morbidity of patients operated on for perforated peptic ulcers. Arch Surg 2001;136:90-94.

81 Lee FY, Leung KL, Lai PB, Lau JW: Selection of patients for laparoscopic repair of perforated peptic ulcer. Br J Surg 2001;88:133136.

82 Malkov IS, Zaynutdinov AM, Veliyev NA, Tagirov MR, Merrell RC: Laparoscopic and endoscopic management of perforated duodenal ulcers. J Am Coll Surg 2004;198:352355 . 
83 Millat B, Fingerhut A, Borie F: Surgical treatment of complicated duodenal ulcers: controlled trials. World J Surg 2000;24:299306.

-84 Robertson GS, Wemyss-Holden SA, Maddern GJ: Laparoscopic repair of perforated peptic ulcers: the role of laparoscopy in generalised peritonitis. Ann R Coll Surg Engl 2000;82:6-10.

-85 Seelig MH, Seelig SK, Behr C, Schonleben K: Comparison between open and laparoscopic technique in the management of perforated gastroduodenal ulcers. J Clin Gastroenterol 2003;37:226-229.

-86 Tsumura H, Ichikawa T, Hiyama E, Murakami Y: Laparoscopic and open approach in perforated peptic ulcer. Hepatogastroenterology 2004;51:1536-1539.

87 Wemyss-Holden S, White SA, Robertson G, Lloyd D: Color coding of sutures in laparoscopic perforated duodenal ulcer: a new concept. Surg Laparosc Endosc Percutan Techn 2002;12:177-179.
88 Bertleff MJ, Halm JA, Bemelman WA, van der Ham AC, van der Harst E, Oei HI, Smulders JF, Steyerberg EW, Lange JF: Randomized clinical trial of laparoscopic versus open repair of the perforated peptic ulcer: the LAMA Trial. World J Surg 2009;33:13681373.

89 Bloechle C, Emmermann A, Zornig C: Laparoscopic and conventional closure of perforated peptic ulcer. Surg Endosc 1997;11: 1226-1227.

90 Boey J, Wong J: Perforated duodenal ulcers. World J Surg 1987;11:319-324.

91 Golash V, Willson PD: Early laparoscopy as a routine procedure in the management of acute abdominal pain: a review of 1,320 patients. Surg Endosc 2005;19:882-885.

$\$ 92$ Lau WY, Leung KL, Kwong KH, Davey IC, Robertson C, Dawson JJ, Chung SC, Li AK: A randomized study comparing laparoscopic versus open repair of perforated peptic ulcer using suture or sutureless technique. Ann Surg 1996;224:131-138.

$\checkmark 93$ Lee KH, Chang HC, Lo CJ: Endoscope-assisted laparoscopic repair of perforated peptic ulcers. Am Surg 2004;70:352-356.

$\checkmark 94$ Lohsiriwat V, Prapasrivorakul S, Lohsiriwat D: Perforated peptic ulcer: clinical presentation, surgical outcomes, and the accuracy of the Boey scoring system in predicting postoperative morbidity and mortality. World J Surg 2009;33:80-85.
95 Matsuda M, Nishiyama M, Hanai T, Saeki S, Watanabe T: Laparoscopic omental patch repair for perforated peptic ulcer. Ann Surg 1995;221:236-240.

$\checkmark 96$ Memon MA: Laparoscopic omental patch repair for perforated peptic ulcer. Ann Surg 1995;222:761-762.

-97 Miserez M, Eypasch E, Spangenberger W, Lefering R, Troidl H: Laparoscopic and conventional closure of perforated peptic ulcer: a comparison. Surg Endosc 1996;10: 831-836.

$>98$ Rossi S: Laparoscopy in gastrointestinal emergency. Eur Surg 2005;36:15-18.

$\checkmark 99$ So JB, Kum CK, Fernandes ML, Goh P: Comparison between laparoscopic and conventional omental patch repair for perforated duodenal ulcer. Surg Endosc 1996; 10:1060-1063.

100 Urbano D, Rossi M, De Simone P, Berloco P, Alfani D, Cortesini R: Alternative laparoscopic management of perforated peptic ulcers. Surg Endosc 1994;8:1208-1211. 